\title{
PENGARUH PEMBELAJARAN PENDIDIKAN AGAMA ISLAM TERHADAP AKHLAK PESERTA DIDIK KELAS VIII DI SMP NEGERI 3 LEMBANG KABUPATEN PINRANG
}

\author{
Nurhudayana $^{1}$, Muh. Djunaidi ${ }^{1}$, Buhaerah ${ }^{1}$ \\ IAIN Parepare \\ Email: Nhurhudayana008@gmail.com
}

\begin{abstract}
The results of this study indicate that Islamic Education is influence of Islamic Religious Education Learning on the morals of grade VIII students in Junior High School 3 Lembang, Pinrang Regency. This can be proven by analyzing data from the results of the questionnaire chosen by respondents and based on the simple linear regression test showing that the value of $Y=20,115+0,647 X$ from the results of the simple linear regression test that the level of Islamic religious education is directly proportional to the morals of students and the hypothesis test the correlation test shows that the value of $R 2=0,576$ or $0.576 \times 100 \%=$ $57.6 \%$ and in the Sig test tcount against H1 shows tilapia $=8.316>$ table 2.006 thus $\mathrm{H} 1$ is accepted and $\mathrm{HO}$ is rejected, thus conclusions can be drawn that Islamic Education influences the morals of students in class VIII at SMP Negeri 3 Lembang Pinrang Regency and the contribution given is $57.6 \%$.
\end{abstract}

Keywords: Islamic Religious Education Learning, Student Morals

\section{ABSTRAK}

Hasil penelitian ini menunjukkan bahwa terdapat Pengaruh Pembelajaran Pendidikan Agama Islam terhadap akhlak peserta didik kelas VIII di SMP Negeri 3 Lembang Kabupaten Pinrang. Hal ini dapat dibuktikan dengan menganalisis data dari hasil angket yang dipilih responden dan berdasarkan pada uji regresi linear sederhana menunjukkaan bahawa nilai $\mathrm{Y}=20,115+0,647 \mathrm{X}$ dari hasil uji regresi linear sederhana bahwa tingkat pendidikan agama Islam berbanding lurus dengan akhlak peserta didik dan pada uji hipotesis pada uji korelasi menunjukkan bahwa 
nilai $\mathrm{R}^{2}=0,576$ atau $0.576 \times 100 \%=57,6 \%$ dan pada uji Sig $\mathrm{t}_{\text {hitung }}$ terhadap $\mathrm{H}_{1}$ menunjukkan nila $\mathrm{t}_{\text {hitung }}=8,316>\mathrm{t}_{\text {tabel }}$ 2,006. dengan demikian $\mathrm{H}_{1}$ diterima dan $\mathrm{H}_{0}$ ditolak, dengan demikian dapat ditarik kesimpulan bahawa Pendidikan Agama Islam berpengaruh terhadap akhlak peserta didik kelas VIII di SMP Negeri 3 Lembang Kabupaten Pinrang dan konstribusi yang diberikan sebesar 57,6\%.

Kata Kunci : Pembelajaran Pendidikan Agama Islam, Akhlak Peserta Didik

\section{PENDAHULUAN}

Pendidkan agama Islam juga perpengaruh banyak terahadap proses perkembangan akhlak peserta didik karena tujuan utama pendidikan agama Islam adalah terwujudnya moral peserta didik yang tinggi serta akhlak yang mulia. Akhlak secara Etimologi berasal dari kata khalaqa yang berarti mencipta, membuat atau menjadikan. Ahklak kata yang berbentuk mufrad, jamaknya adalah khuluqun, yang berarti perangai, tabiat, adat atau khalqun yang berarti kejadian, buatan atau ciptaan. Jadi, Akhalak secara etimologi berarti adat, tabiat, atau perilaku yang di buat oleh manusia. Secara kebahsaan akhlak bisa baik ataupun buruk tergantung pada tata nilai yang dipakai sebagai landasan. ${ }^{1}$

Membentuk akhlak peserta didik yang harus dilakukan sebagai guru propesional, yaitu di tuntut untuk membuat rancangan pembelajaran yang efektif dan menyenangkan di dalam proses pembelajaran (pendidikan agama Islam), karena dalam pembelajaran pendidikan agama Islam begitu banyak materi-materi yang dapat kita gunakan untuk membentuk akhlak peserta didik dan juga sebagai kunci untuk menghadapi permasalahan yang terjadi saat ini, jadi dalam pendidikan agama Islam harus ditingkatkan agar proses pembelajaran berjalan lancar dan menghasilkan peserta didik yang sesuai dengan tujuan pendidikan nasional yaitu peserta didik yang berakhlak sehingga bisa menjadi contoh di sekolahnya, keluarganya, dan masyarakat sekitarnya.

Berdasarkan latar belakang di atas peneliti termotivasi untuk melakukan penelitian ini dan mengangkat judul: Pengaruh Pembelajaran

${ }^{1}$ Zainuddin Ali, Pendidikan Agama Islam, (Jakarta: PT Bumi Aksara, 2010), h.29. 
Pendidikan Agama Islam Terhadap Akhlak Peserta Didik Kelas VIII di SMP Negeri 3 Lembang Kabupaten Pinrang .

Berdasarkan pemaparan latar belakang di atas, dapat di rumuskan permaslahan sebagai berikut:

1. Bagaimana Pembelajaran Pendidikan agama Islam di SMP Negeri 3 Lembeng kelas VIII?

2. Bagaimana pembalajan pendidikan agama Islam terhadap akhlak peserta didik di SMP Negeri 3 Lembang Kabupaten Pinrang?

3. Apakah terdapat pengaruh pendidikan agama Islam terhadap akhlak peserta didik di SMP Negeri 3 Lembang kelas VIII?

Berdasarkan dari rumusan masalah di atas, maka dapat di kita ketehaui tujuan dari penelitian ini adalah :

1. Menegtahui pembelajaran pendidikan agama Islam di SMP negeri 3 Lembang Kabupaten Pinrang.

2. Mendapatkan informasi mengenai pengajaran pendidikan agama Islam terhadap akhlak peserta didik di SMP Negeri 3 Lembang Kabupaten Pinrang.

3. Mengetahui pengaruh pendidikan agama Islam terhadap akhlak peserta didik di SMP Negeri 3 Lembang Kabupaten Pinrang.

Adapun keguanaan penelitian adalah sebagai berikut:

1. Secara teoritis, hasil penelitian dapat digunakan sebagai upaya meningkatkan hasil belajar peserta didik pada bidang studi Pendidikan Agama Islam di SMP Negeri 3 Lembang.

2. Secara Praktis

1) Bagi sekolah, sebagai sumbangan pemikiran dalam meningkatkan kualitas pembelajaran Pendidikan Agama Islam sehingga dapat meningkatkan hasil belajar peserta didik.

2) Bagi pendidik, memberikan inspirasi bagi pendidik dalam menentukan model pembelajaran sesuai dengan materi dan kondisi peserta didik.

3) Bagi peneliti, sebagai bekal untuk meningkatkan pengetahuan serta menambah wawasan dibidang keguruan agar nantinya dapat melaksanakan tugas sebaik-baiknya.

\section{METODE PENELITIAN}

Jenis pendekatan dan penelitian ini adalah pendekatan kuantitatif. Penelitian kuantitatif adalah penelitian yang datanya berbentuk kata, 
kalimat, skema dan gambar, ${ }^{2}$, yang bisa diperoleh dari hasil angket, kemudian di analisa sedemikian rupa untuk kemudian dibandingkan dengan hipotesis. Pendekatan yang digunakan yaitu kuantitatif asosiatif. Dan hasil penelitian ini bertujuan untuk memperoleh informasi tentang Pengaruh Pembelajaran Pendidikan agama Islam terhadap akhlak peserta didik kelas VIII di SMP Negeri 3 Lembang Kabupaten Pinrang.

Observasi adalah alat pengumpulan data yang dilakukan dengan cara mengamati dan mencatat secara sistematik gejala-gejala yang diselidiki. Dalam pengertian yang lain teknik observasi adalah cara menganalisis dan mengadakan pencatatan secara sistematis mengenai tingkah laku dengan melihat atau mengamati secara langsung keadaan lapangan agar peneliti memperoleh gambaran yang lebih luas tentang permasalahan yang diteliti. observasi yang telah dilakukan oleh penulis, penulis mengambil data dengan mengadakan pengamatan secara langsung serta mencatat hal-hal yang ada hubungannya dengan penelitian yang akan dilakukan dalam rangka menyempurnakan penelitian.

Angket merupakan pertanyaan-pertanyaan yang telah tersusun secara kronologis dari yang umum mengarah pada khusus untuk diberikan pada responden/informan yang umumnya merupakan daftar pertanyaan lazim. Dalam pengertian yang lain angket merupakan teknik pengumpulan data dengan cara memberi sejumlah pertanyaan atau pernyataan dalam bentuk tertulis dan dijawab secara tertulis pula oleh responden.

Salah satu teknik pengumpulan data yang tidak kalah pentingnya dengan teknik yang lainnya yaitu teknik pengumpulan data dengan dokumentasi, yaitu mencari data mengenai hal-hal variabel yang berupa catatan, transkrip, buku, surat kabar, prasasti, notulen rapat, lengger, agenda dan sebagainya. Dibandingkan dengan metode lain, maka metode ini agak tidak begitu sulit, dalam arti apabila ada kekeliruan sumber datanya masih tetap, belum berubah. Dengan metode dokumentasi yang diamati bukan benda hidup tetapi benda mati. ${ }^{3}$

Teknik dokumentasi dalam penelitian ini digunakan untuk memperoleh sejumlah data melalui pencatatan dari sejumlah dokumen atau

\footnotetext{
${ }^{2}$ Sugiyono, Metode Penelitian Kuantitatif Kualitatif, (cet. II Bandung Alphabet,2010) h.30

${ }^{3}$ Husain dan Setiady Akbar. Metodologi Penelitian Sosial (Cet. II; Jakarta: Bumi Aksara, 2009), h. 42
} 
bukti tertulis seperti keadaan populasi, struktur organisasi, data-data sekolah dan sebagainya.

1. Instrumen yang digunakan untuk observasi berupa chek list. Dilakukan saat pengamatan berlangsung di dalam kelas.

2. Instrumen yang digunakan untuk dokumentasi yaitu berupa Arsip, grafik, buku-buku, peraturan-peraturan, catatan-catatan harian, data peserta didik dan sebagainya.

\section{HASIL PENELITIAN}

Berdasarkan pengujian analisis data, telah diperoleh nilai pada masing-masing variabel, sebagai berikut:

1. Pembelajaran Pendidikan Agama Islam Kelas VIII di SMP Negeri 3 Lembang Kabupaten Pinrang

Berdasarkan hasil analisis data pada skor pada rumusan masalah pertama pada variabel pendidikan agama Islam (X). Skor total variabel pengaruh pendidikann agama Islam (X) yang diperoleh dari hasil penelitian adalah 2269 skor teoritik tertinggi variabel ini tiap responden adalah 17 x 4 $=68$, karena jumlah responden 53 orang, maka skor kriterium adalah $68 \mathrm{x}$ $53=3604$. Sehingga, pengaruh pendidikan agama Islam adalah 2269: 3604 $=0,6295$ atau $62,95 \%$ dari kriteria yang ditetapkan. Jadi, dapat disimpulkan bahwa pengaruh pendidikan agama Islam termasuk kategori rendah.

2. Pembelajaran Pendidikan Agama Islam Terhadap Akhlak peserta didik Kelas VIII di SMP Negeri 3 Lembang Kabupaten Pinrang

Berdasarkan hasil analisis data skor pada rumusan masalah kedua atau pada variabel pembentuk akhlak (Y). Skor total variabel akhlak peserta didik yang diperoleh dari hasil penelitian adalah 2566 , skor teoritik tertinggi variabel ini tiap responden adalah $20 \times 4=80$ karena jumlah responden 53 orang, maka skor kriterium adalah $80 \times 53=4240$. Sehingga, akhlak peserta didik dalah $2566: 4240=0,605$ atau 60,5\% dari kriterium yang ditetapkan. Jadi, dapat disimpulkan akhlak peserta didik termasuk kategori rendah.

3. Pengaruh Pendidikan Agama Islam terhadap akhlak peserta didik kelas VIII di SMP Negeri 3 Lembang kabupaten Pinrang.

Berdasarkan hasil hipotesis terdapat pengaruh yang signifikan antara variabel Pendidikan Agama Islam X terhadap. Sebagaimana hipotesis pada 
uji instrument variabel $\mathrm{X}$ dan $\mathrm{Y}$ menunjukan bahwa $H_{1}$ diterima dan $H_{0}$ di tolak, sebagaimana pada uji signifikan pada uji korelasi yaitu nilai 0,759> 0,05 dapat disimpulkan bahwa $H_{1}$ diterima dan $H_{0}$ ditolak dalam artian bahwa terdapat hubungan antara variabel pendidikan agama Islam (X) dan variabel akhlak peserta didik (Y).

Berdasarkan hasil uji persamaan regresi linear sederhana menunjukan bahwa variabel $\mathrm{X}$ dan $\mathrm{Y}$ diperoleh persamaan regresi $\mathrm{Y}=$ $20,115+0,647 \mathrm{X}$. Selanjutnya pengujian hipotesis dilakukan dengan uji $t_{\text {hitung }} 8,316$ dan nilai $t_{\text {tabel }} 2,007$ artinya ada pengaruh yang signifikan antara variabel pendidikan agama Islam (X) terhadap variabel akhlak peserta didik (Y). Dari hasil analisis dikemukakan bahwa hipotesis ini memiliki pengaruh antara variabel pendidikan agama Islam (X) terhadap variabel pembentukan akhlak peserta didik (Y) atau terdapat pengaruh pendidikan agama Islam terhadap akhlak peserta didik kelas VIII di SMP Negeri 3 Lembang Kabupaten Pinrang dan diterima secara signifikan. Dapat dilihat dari korelasi nilai $\mathrm{R}=0,759(\mathrm{R} \neq 0)$, besarnya nilai korelasi $\mathrm{R}^{2}=0$, 576 atau $0.576 \times 100 \%=57,6 \%$ menunjukkan derajat hubungan yang kuat anatar varibel Pendidikan Agama Islam (X) dan variabel akhlak peserta didik (Y) dengan sumbangan (konstribusi) sebesar 57,6\% dan sisanya dipengaruhi variabel lain yaitu sebesar $100 \%-57,6 \%=42,4 \%$ dipengaruhi variabel lain.

\section{PEMBAHASAN}

Sebelum peneliti menjelaskan mengenai hasil penelitian, maka terlebih dahulu peneliti mendesripsikan bahwa pendidikan agama Islam adalah hal yang sangat penting terhadap dunia pendidikan karena pendidikan agama Islam sangat berguna dalam membentuk akhlak seorang individi (peserta didik), dimana peran seorang guru harus memberikan motivasi atau dorongan kepada peserta didik apakah itu melalui ide-ide atau upaya yang dimiliki oleh seorang guru agar pesrta didik terdorong belajar, mau belajar dan tertarik untuk terus mempelajari apa yang telah teraktualisasikan di dalam kurikulum pendidikan agama Islam. Dalam pendidikan agama Islam terdapat beberapa pokok pembelajaran diantaranya keimanan (akidah), pendidikan ibadah dan pendidikan ibadah. 
Penelitian ini dilaksanakan di kelas VIII SMP Negeri 3 Lembang kabupaten Pinrang dengan jumlah populasi 140 peserta didik dan yang menjadi sampel sebanyak 53 peseta didik. Teknik yang dilakukan dalam penelitian ini menggunakan teknik proposive sampling. Teknik pengambilan anggota sampel dari populasi dengan cara menentukn sampel dengan pertimbangan tertentu. Pada penelitian ini teknik pengumpulan data yang digunakan adalah observasi, angket, dan dokumentasi. Langkah pertama yang dilakukan peneliti adalah dengan melakukan observasi dimana peneliti mengamati aktivitas di lingkungan sekolah yaitu keadaan lingkungannya, dan sikap peserta didiknya.

Pembelajaran Pendidikan agama Islam adalah usaha sadar yang dilakukan oleh guru pendidikan agama Islam agar peserta didik dapat meyakini, memahami, mendalami dan mengamalkan agama Islam melalui pengajaran-pengajan agama menurut syariat Islam. Hasil penelitian menunjukkan bahwa skor variabel pendidikan agama Islam berada pada:

Tabel 4.1 Rangkuman Statistik Deskriptif (variabel X)

Pendidikan Agama Islam

Statistics

\begin{tabular}{|c|c|c|}
\hline $\begin{array}{l}\mathrm{N} \\
\text { Mean } \\
\text { Median } \\
\text { Mode } \\
\text { Std. Deviation } \\
\text { Variance } \\
\text { Range } \\
\text { Minimum } \\
\text { Maximum } \\
\text { Sum }\end{array}$ & $\begin{array}{l}\text { Valid } \\
\text { Missing }\end{array}$ & $\begin{array}{l}53 \\
0 \\
42.81 \\
42.00 \\
49 \\
8.773 \\
76.964 \\
37 \\
23 \\
60 \\
2269\end{array}$ \\
\hline
\end{tabular}

Sumber data: Aplikasi IMB Statistik SPSS 21.

Hasil penelitian menunjukkan bahwa skor variabel pendidikan agama Islam berada pada nilai minimum 23 dengan nilai maksimum 60, median 42,00. modus 49, varians 76,964 dan standar deviasi 8,773. Distribusi frekuensi pembelajaran pendidikan agama Islam (X) memiliki skor yang diperoleh dari responden (peserta didik) yang valid dengan nilai mode 49 yang memiliki 5 frekuensi sebanyak 9,4\% dengan demikian jumlah 53 responden. Hal demikian tergambar jelas bahwa tebel distribusi frekuensi 
pembelajaran pendidikan agama Islam (X), dengan demikian variabel $\mathrm{X}$ dapat dilihat dalam bentuk diagram batang dan lingkaran sebagai berikut:

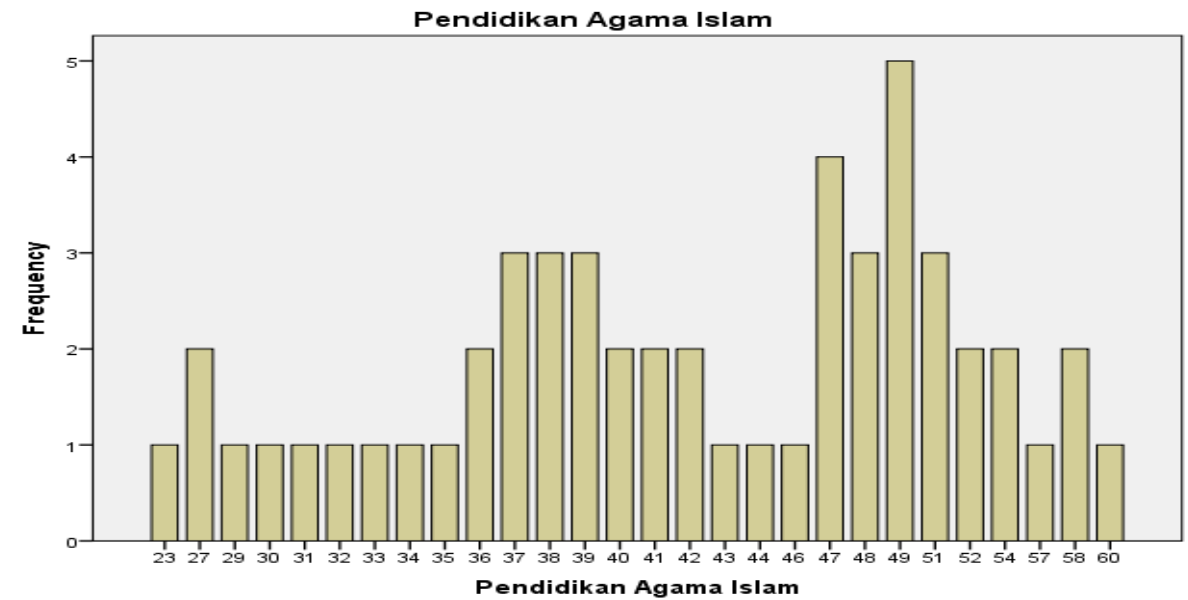

Gambar 4.1 Diagram batang variabel X ( pembelajaran Pendidikan Agama Islam)

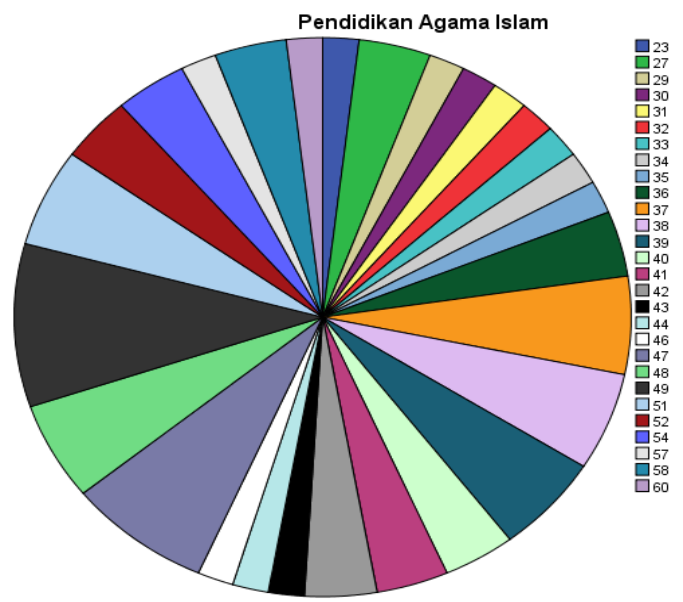

Gambar 4.2 Diagram lingkaran variabel X (Pendidikan Aagama Islam)

Sesuai dengan diagram tabel dan lingkaran bahwa distribusi frekuensi pendidikan agama Islam (X) memiliki skor dan total diperoleh pada setiap responden (peserta didik) dan nilai 23, 29, 30, 31, 32, 33, 34, 35, 43, 44, 57 dan 60 masing-masing memiliki 1 frekuensi (1,9\%) sedangkan 
nilai 27, 36, 40, 41, 42, 52, 54, dan 58 masing-masing memiliki 2 frekuensi $(3,8 \%)$, sedangkan nilai $37,38,39,48$ dan 51 masing-masing memiliki 3 frekuensi $(5,7 \%)$, sedangkan nilai 47 memiliki frekuensi $4(7,5 \%)$.

Berdasarkan pada tabel 4.2 distribusi frekuensi pendidikan agama Islam di atas menunjukkan bahwa skor yang diperoleh oleh responden (peserta didik) 53 dan jumlah persen yang diperoleh adalah $100 \%$.

Selanjutnya setelah data dalam bentuk tabel distribusi frekuensi, langkah berikutnya adalah penyajian data dalam bentuk histogram. Adapaun bentuk histogram sebagai berikut:

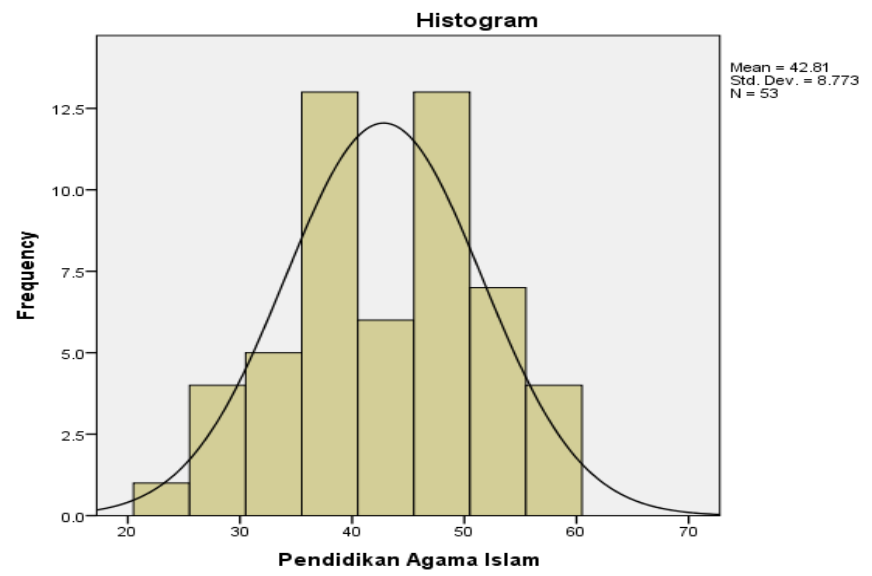

Gambar 4.3 Histogram pendidikan agama Islam

Berdasarkan data yang terlihat pada tabel distribusi frekuensi di atas, jika dibandingkan dengan nilai rata-rata menunjukkan bahwa skor Pengaruh pendidikan agama Islam berada pada skor kelompok rata-rata sebanyak 5 responden $(9,4 \%)$ yang berada pada dibawah skor rata-rata adalah sebanyak 37 orang $(70,2 \%)$, dan yang berada pada kelompok diatas nilai rata-rata sebanyak 11 responden $(20,9 \%)$. Penentuan kategori dari skor kepribadian pendidik dilakukan dengan menggunakan kriteria bentuk persentase sebagai berikut:90\% - 100\% kategori sangat tinggi

$80 \%-89 \% \quad$ kategori tinggi

$70 \%-79 \% \quad$ kategori sedang

$60 \%-69 \%$ kategori rendah

$0 \%-59 \% \quad$ kategori sangat rendah. ${ }^{4}$

\footnotetext{
${ }^{4}$ Suharsimi Arikunto, Evaluasi Pendidikan (Jakarta: Bina Aksara, 1986), h. 54.
} 
Skor total variabel pengaruh pembelajaran pendidikann agama Islam yang diperoleh dari hasil penelitian adalah 2269 skor teoritik tertinggi variabel ini tiap responden adalah 17 x $4=68$, karena jumlah responden 53 orang, maka skor kriterium adalah 68 x $53=3604$. Sehingga, pengaruh pembelajaran pendidikan agama Islam adalah $2269: 3604=0,6295$ atau $62,95 \%$ dari kriteria yang ditetapkan. Jadi, dapat disimpulkan bahwa pengaruh pembelajaran pendidikan agama Islam termasuk kategori rendah. Hal tersebut sesuai dengan hasil pengamatan di lapangan bahwa pengaruh pembelajaran pendidikan agama Islam dapat dikatakan kurang baik terkhusus untuk pendidik mata pelajaran Pendidkan agama Islam.

Akhlak adalah perangai serta tingkah laku dan kebiasaan yang terdapat pada diri seseorang yang telah melekat, dilakukandan dipertahankan secara terus menerus. Faktor-faktor yang mempengaruhi pembentukan akhalak pada khususnya dan pendidikan pada umumnya, ada tiga aliran yang pertama aliran nativisme, menurut aliran nativisme bahwa faktor yang palinga berpengaruh terhadap pembentukan diri seseorang adalah faktor pembewaan dari dalam yang bentuknya dapat berupa kecenderungan, bakat, akal, dan lain-lain. Hasil penelitian menunjukkan bahwa skor variabel akhlak peserta didik antaranya.

Tabel 4.3 Rangkuman hasil statistik deskriptif variabel (Y)

\section{Statistics}

Akhlak Peserta Didik

\begin{tabular}{|l|r|}
\hline \multicolumn{1}{|c|}{$\quad$ Valid } & 53 \\
Mean & Missing \\
Median & 0 \\
Mode & 48.42 \\
Std. Deviation & 50.00 \\
Variance & 50 \\
Range & 7.584 \\
Minimum & 57.517 \\
Maximum & 30 \\
Sum & 30 \\
\hline
\end{tabular}

Sumber data: Aplikasi IMB Statistik SPSS 21. 
Distribusi frekuensi variabel pengaruh pembelajaran pendidikan agama Islam terhadap akhlak peserta didik berada pada nilai minimum 30 dengan nilai maksimum 60 , median 50,00, modus 50, varians 57,517, dan standar deviasi 7.584. distribusi akhlak peserta didik (Y) memiliki skor yang diperoleh dari responden (peserta didik) yang valid dengan nilai mode 50 yang memiliki 9 frekuensi sebanyak (17.0\%) dengan demikian jumlah 53 responden. Hal demikian tergambar jelas bahwa tebel distribusi frekuensi akhlak peserta didik (Y), dengan demikian variabel Y dapat dilihat dalam bentuk diagram batang dan lingkaran sebagai berikut:

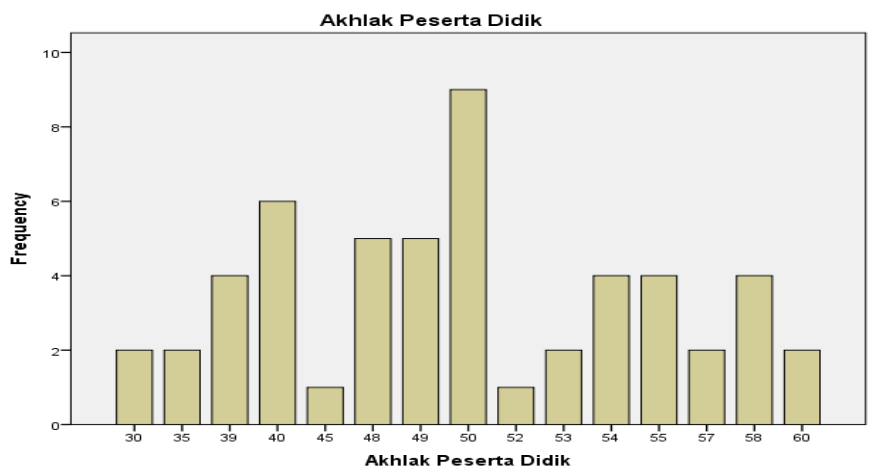

Gambar 4.4 Diagram batang variabel Y (akhlak peserta didik) berikut:

Diagram variabel dapat pula ditunjukkan pada gambar 4.5 sebagai

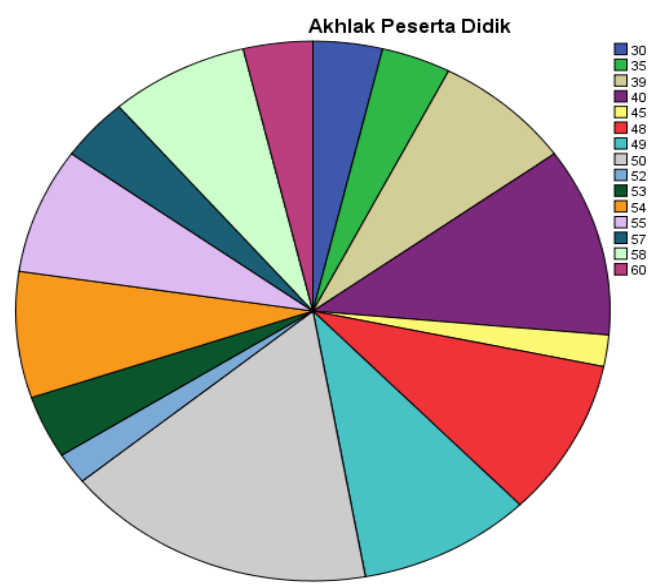

Gambar 4.5 Diagram lingkaran variabel Y 
Sesuai dengan diagram tabel dan lingkaran bahwa distribusi frekuensi akhlak peserta didik (Y) memiliki skor dan total diperoleh pada setiap responden (peserta didik) dan nilai 45, dan 52 masing-masing memiliki 1 frekuensi (1,9\%), sedangkan nilai 30, 35, 53, 57, dan 60 masingmasing memiliki 2 frekuensi (3,8\%), sedangkan nilai 39, 54, 55, dan 58 masing-masing memiliki 4 frekuensi $(7,5 \%)$, sedangkan nilai 48, dan 49 memiliki 5 frekuensi(9,4\%), sedangkan nilai 40 memiliki 6 frekuensi $(11,3 \%)$.

Berdasarkan pada tabel 4.4 distribusi frekuensi akhlak peserta didik diatas menunjukkan bahwa skor yang diperoleh oleh responden (peserta didik) 53 dan jumlah persen yang diperoleh adalah $100 \%$.

Selanjutnya setelah data dalam bentuk tabel distribusi frekuensi, langkah berikutnya adalah penyajian data dalam bentuk histogram. Adapaun bentuk histogram sebagai berikut:

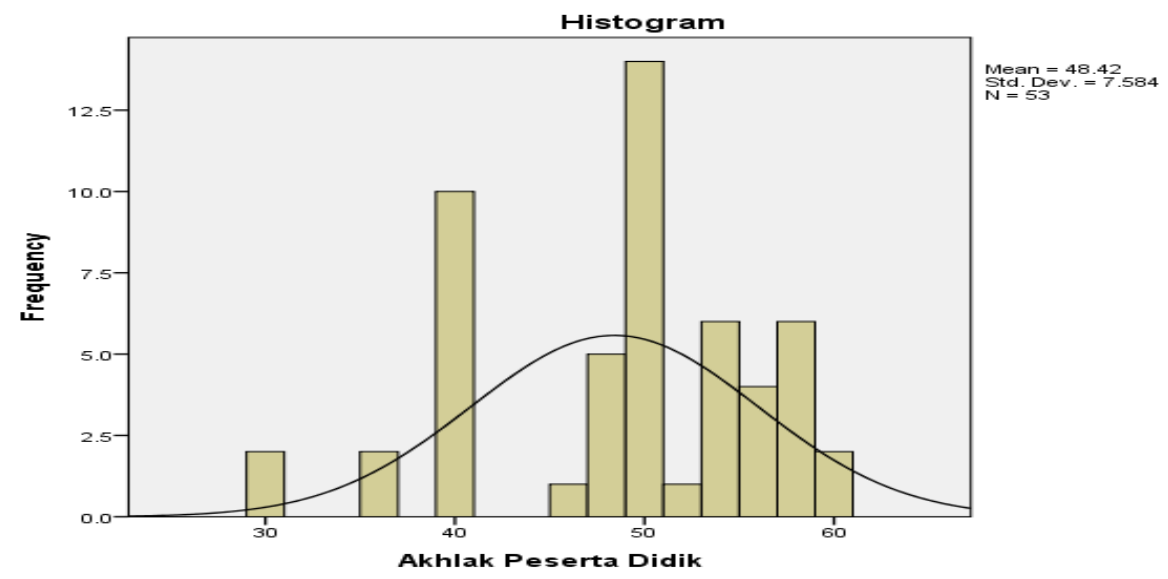

Gambar 4.6 Histogram akhlak peserta didik

Berdasarkan data yang terlihat pada tabel distribusi frekuensi di atas, jika dibandingkan dengan nilai rata-rata menunjukkan bahwa skor akhalak peserta didik berada pada skor kelompok rata-rata sebanyak 9 responden $(17,0 \%)$ yang berada pada dibawah skor rata-rata adalah sebanyak 25 orang $(47,1 \%)$ dan yang berada pada kelompok diatas nilai rata-rata sebanyak 19 responden (35,8\%). Penentuan kategori dari skor akhalak peserta didik dilakukan dengan menggunakan kriteria bentuk persentase sebagai berikut: 


$\begin{array}{ll}90 \%-100 \% & \text { kategori sangat tinggi } \\ 80 \%-89 \% & \text { kategori tinggi } \\ 70 \%-79 \% & \text { kategori sedang } \\ 60 \%-69 \% & \text { kategori rendah } \\ 0 \%-59 \% & \text { kategori sangat rendah. }\end{array}$

Skor total variabel akhlak peserta didik yang diperoleh dari hasil penelitian adalah 2566 , skor teoritik tertinggi variabel ini tiap responden adalah $20 \times 4=80$ karena jumlah responden 53 orang, maka skor kriterium adalah $80 \times 53=4240$. Sehingga, akhlak peserta didik dalah $2566: 4240=$ 0,605 atau $60,5 \%$ dari kriterium yang ditetapkan. Jadi, dapat disimpulkan akhlak peserta didik termasuk kategori rendah.

\section{KESIMPULAN}

Berdasarkan pengujian analisis data yang diuraikan dalam BAB VI skripsi ini, tentang pendidikan agama Islam dan pengaruhnya terhadap akhlak peserta didik jelas VIII di SMP Negeri 3 Lembang kabupaten Pinrang, maka dapat ditarik kesimpulan sebagai berikut:

Hasil analisis data deskriptif menunjukan bahwa pengajaran Pendidikan Agama Islam terhada akhlak peserta didik di SMP Negeri 3 Lembang kabupaten Pinrang dikategorikan rendah berdasarkan hasil analisis data yaitu skorpada skor pada rumusan masalah pertama pada variabel pendidikan agama Islam (X). Skor yang diperoleh variabel pengaruh pendidikann agama Islam (X) sebesar 2269 dan 4 × 17 x $53=$ 3,604 sebagai nilai deskriptif nilai $\boldsymbol{\Sigma} x=2269: 3604=0,6295$ atau 62,95 $\%$. Menunjukan bahwa upaya dalam meningkatkan pendidikan agama Islam di SMP Negeri 3 Lembang kabupaten Pinrang telah dilakukan dengan baik dan memberikan dampak positif bagi peserta didik. Untuk meningkatkan pendidikan agama Islam harus ada upaya dalam meningkatkan pendidikan agama Islam perlu upaya untuk mengubah cara mengajar dengan menggunakan metode-metode yang memudahkan peserta didik terdorong mau belajar, tertarik untuk mengaplikasikannya dalam kehidupan seharihari dan terus mempelajari apa yang teraktualisasikan dalam kurikulum agama Islam.

Hasil analisis data deskriptif pada rumusan masalah kedua atau pada variabel pembentuk akhlak (Y) adalah 2566 dan $4 \times 20 \times 53=4240$.

\footnotetext{
${ }^{5}$ Suharsimi Arikunto, Evaluasi Pendidikan, h. 54.
} 
Sehingga, akhlak peserta didik dalah $2566: 4240=0,605$ atau 60,5\%. Hal ini menunjukan bahwa dalam menunjukan bahwa dalam membentuk akhlak peserta didik SMP Negeri 3 Lembang kabupaten Pinrang memberikan materi tentang pendidikan agama Islam.

Terdapat pengaruh yang signifikan pendidikan agama Islam terhadap akhlak peserta didik kelas VIII di SMP Negeri 3 Lembang Kabupaten Pinrang. Berdasarkan pada hasil uji hipotesis dengan menngunakan rumus regresi linear sederhana dari pengujian menunjukan $\mathrm{Y}=20,115+0,647 \mathrm{X}$ dengan artian bahwa variabel pendidikan agama Islam (X) berpengaruh positif terhadap variabel akhlak peserta didik (Y) dan dalam $t_{\text {hitung }}$ sebesar 8,316 dan nilai $t_{\text {tabel }}$ sebesar 2,007, hal ini berarti $\mathrm{H}_{0}$ ditolak dan $\mathrm{H}_{1}$ diterima. Berarti artinya bahwa pendidikan agama Islam berpengaruh terhadap pembentukan akhlak peserta didik kelas VIII di SMP Negeri 3 Lembang Kabupaten Pinrang.

\section{DAFTAR PUSTAKA}

Ali, Zainuddin. 2010. Pendidikan Agama Islam, Jakarta: PT Bumi Aksara. Arikunto, Suharsimi. 1986. Evaluasi Pendidikan Jakarta: Bina Aksara.

Husain dan Setiady Akbar. 2009. Metodologi Penelitian Sosial, Cet. II; Jakarta: Bumi Aksara.

Sugiyono.2010. Metode Penelitian Kuantitatif Kualitatif, cet. II Bandung Alphabet. 